Fernando de Aragón, Duque de Calabria y Virrey de Valencia (viudo de doña Germana de Foix), y, posteriormente, después de su boda con el citado caballero el 13 de enero de 1541, pasó a habitar el Palacio del Real en Valencia, lugar de residencia de los virreyes.

Sin embargo, doña Mencía no se olvidó de su castillo de Jadraque y en alguna ocasión mandó repararlo allí donde fuera menester. Así, en 1547, don Antonio de Montalvo, alcalde del Cid y gobernador y justicia mayor de Jadraque, en nombre de su excelencia, mostró, junto al mayordomo Juan Blas, toda la fortaleza al maestro de cantería Pedro Belez, residente en esa villa, para que éste opinara lo que era necesario arreglar. Una vez visitado el castillo, el maestro Belez expuso lo que, a su entender, debía repararse, siendo redactado por el escribano Diego de Madrid, el 10 de agosto de $1547^{19}$. Los arreglos consistían en lo siguiente: reedificar un cubo de la muralla que estaba caído; levantar, de nuevo, un trozo de barbacana cercano a la puerta falsa, ya que por allí podían entrar los ganados a pacer en la ronda; reparar los cimientos y agujeros de algunos muros, pues podrían venirse abajo; y cubrir con tejas la cocina que estaba fuera y que se hizo cuando pasó por allí el emperador, pues si seguía descubierta se perdería toda la madera e, incluso, el edificio.

Al morir doña Mencía sin sucesión, en 1554, el castillo de Jadraque pasó a ser propiedad de su hermana María, heredera del marquesado del Cenete y casada, como hemos visto, con el Conde de Saldaña. A partir de ese momento, el citado castillo se vinculará a la Casa del Infantado.

Juana Hidalgo Ogáyar Universidad de Alcalá

\title{
SOBRE LA CRONOLOGÍA Y EL AUTOR DE TRES TALLAS EN MADERA DEL INSTITUTO DE VALENCIA DE DON JUAN
}

A partir de mediados del siglo xvi se asientan en Toledo, centro clave del arte escultórico castellano, maestros que, procedentes de focos artísticos diversos, son del máximo interés para estudiar la evolución de la escultura castellana. Ellos enseñan a los maestros de la vieja escuela, fuese Copin de Holanda u otros, los adelantos que los grandes escultores de Castilla la Vieja habían introducido en la plástica española.

Esta escuela más progresista integrada por Juan Bautista Vázquez el Viejo, Nicolás de Vergara el Viejo y Diego de Velasco el Viejo, marca el camino hacia el Sur que desde el segundo tercio del siglo XVI se ha iniciado, de forma paralela al desplazamiento de los centros vitales de la vida española, en su más amplio sentido.

Asimismo en sus talleres se formarán los seguidores de su arte, sus propios hijos y otros, algunos de los cuales sea Juan Bautista Vázquez el Mozo o Diego de Velasco el Mozo, seguirán la ruta marcada por sus ancestros trasladándose a Sevilla.

Al estudiar las hermosas tallas, hechas en madera de nogal, representando «tres Profetas o Apóstoles», que forman parte de la colección de escultura del Instituto Valencia de don Juan, figurando en el inventario con los números: 4.294, 4.297 y 4.323, nos embelesan su ternura, su delicadeza y el cuidado con que están talladas las minucias de cabellos y plegados. Se consideran de gran interés aunque no estén documentadas.

Para admirar estas obras en su potencia expresiva, deberíamos tener en cuenta que pudieron ser concebidas para ser contempladas a distancia, no cercanas y con la cruda luz del $\mathrm{Mu}$ -

${ }^{19}$ Archivo Palau-Requesens, leg. 157-31.

AEA, LXXVIII, 2005, 310, pp. 175 a 201 

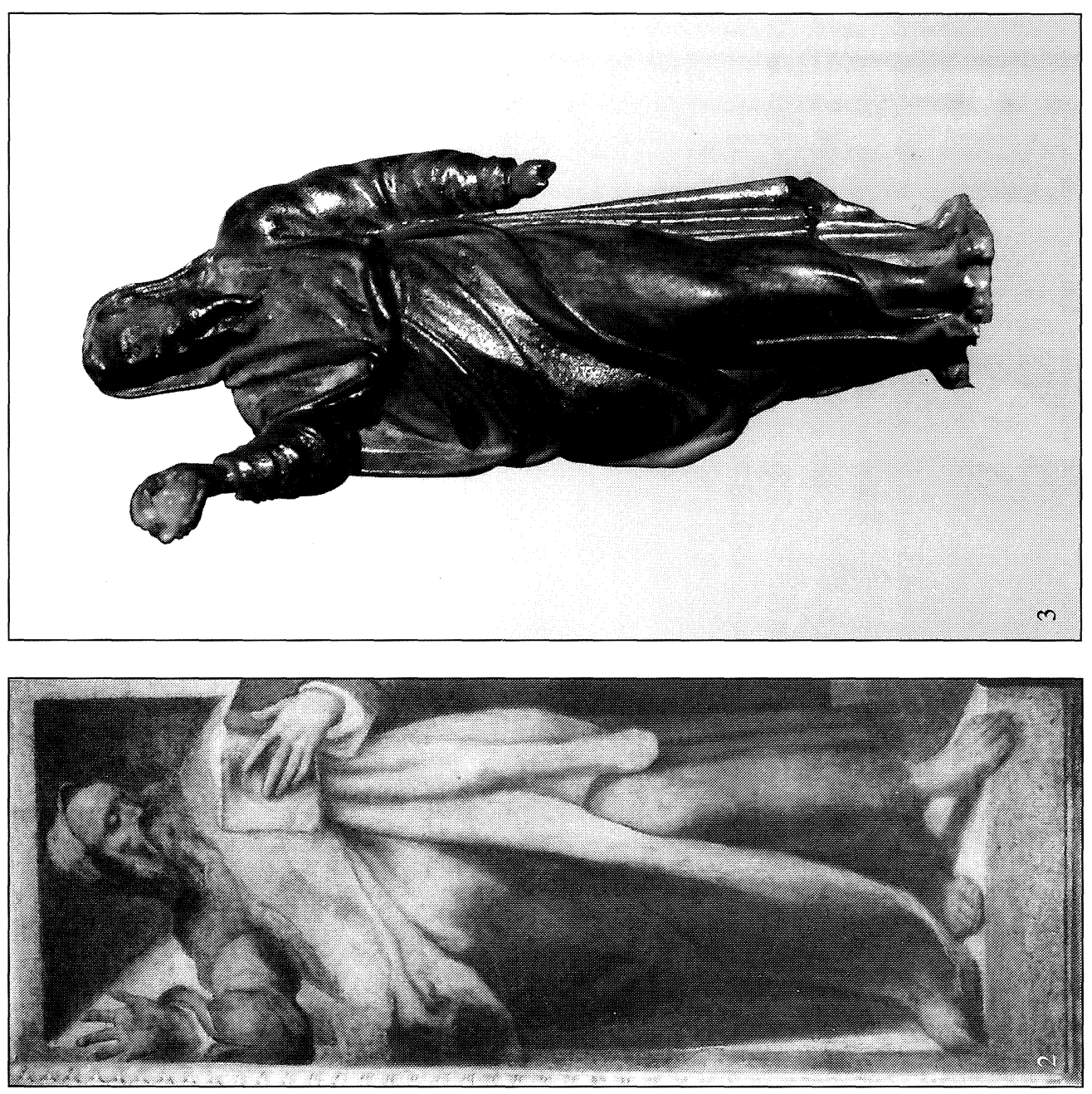

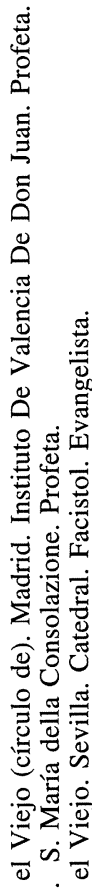

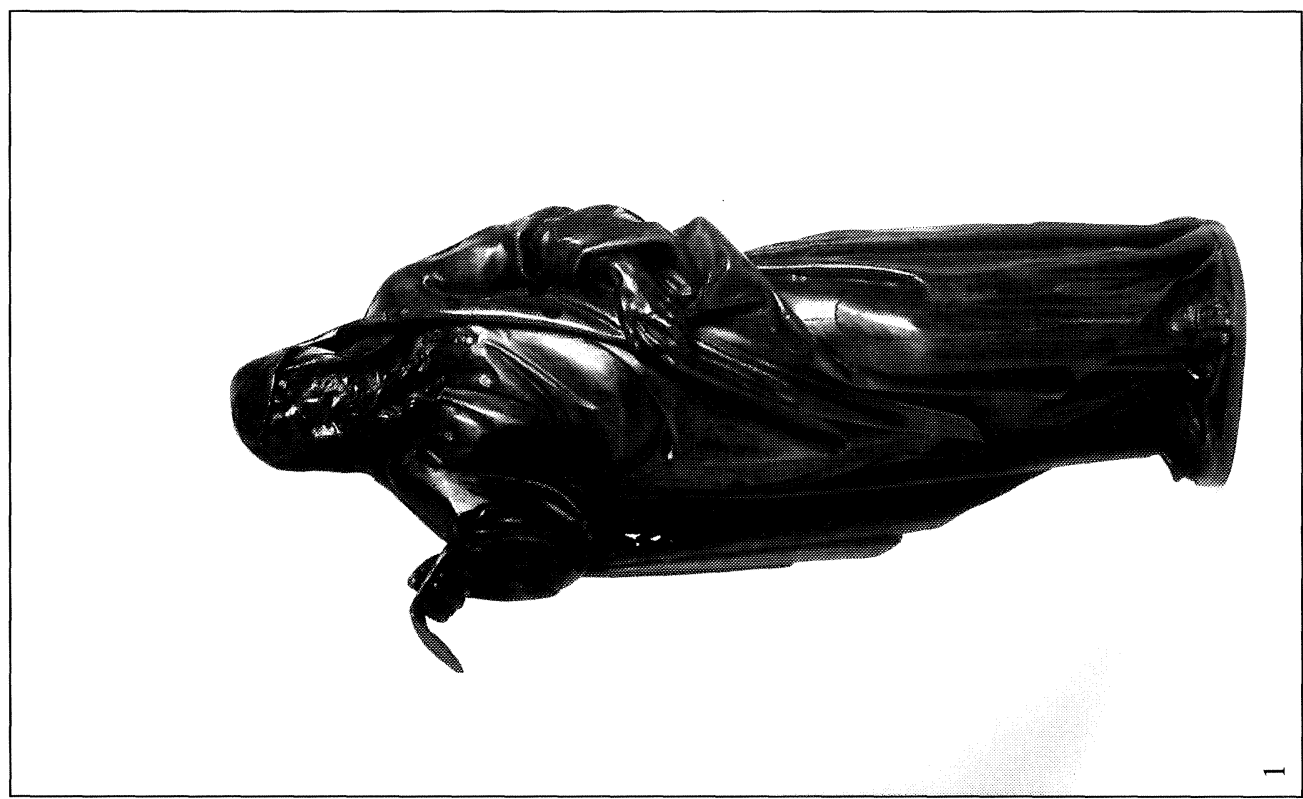

仓ึ

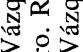

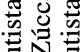

政

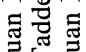

.

-ंतिल

的野野注

AEA, LXXVIII, 2005, 310, pp. 175 a 201 
seo. Su peculiar actitud tenía que resultar entonces mucho más llamativa. El estudio de las condiciones materiales, su delicado trabajo en bulto redondo y ausencia de policromía pudieran hacernos sugerir fueron figurillas para ver directamente o formar parte de un conjunto, como tenebrario, facistol o monumento similar, que no la exigiera, o bien incluso de un retablo como tantas otras que aparecen en los intercolumnios en el caso de que en su día estuvieran policromadas.

Según consta en el Boletín de la Sociedad Española de Excursiones, pertenecieron a la colección de D. Carlos J.Ortriz de Taranco, el cual aseguraba haberlas adquirido en Sevilla, y que eran obra del célebre escultor Torrigiano, sin que pueda fundamentarse la atribución; su hermosa ejecución, marcado sabor florentino y proceder de la ciudad donde murió el citado artista, eran circunstancias que al parecer del artículo daban muchos visos de certeza a su atribución ${ }^{1}$.

El hecho de que la autoría no se haya constatado documentalmente y su estudio estilístico contradicen la afirmación.

La fecha de la muerte de Torrigiano, 1528 es temprana a la hora de ubicar la realización de estas piezas claramente manieristas. Considerando el «manierismo» una manifestación principal del arte renacentista, que comienza en 1520, manteniendo vigencia en Italia hasta final de siglo y prolongándose en España a comienzos del siguiente, el tratamiento plástico de dichas obras nos inclina a situarlas más bien en la segunda mitad del siglo xvI, momento en que este estilo ha alcanzado más desarrollo entre nuestros escultores.

En esta etapa del «manierismo» anterior al Greco es de observar sobre todo la técnica del «punto de vista interior», que conduce al alargamiento, contorneamiento y estiramiento de las figuras.

El recurso para la espiritualización de las figuras se obtiene alargando el canon para desmaterializarlas; la tendencia a la acentuación del contraposto genera la figura serpentinata, y el estiramiento de las figuras buscando un efecto expresivo da lugar a actitudes muy movidas (agitación, desasosiego) ${ }^{2}$.

Esta estética tiene su máximo desarrollo en el escultor Alonso Berruguete, artista de formación ecléctica, en la que, siguiendo el consejo de Leonardo, va «observando ahora esto, luego aquello y reuniendo un haz de cosas notables y elegidas entre las mejores», e integrando esta diversidad como fundamento de su originalidad, tan deseada y buscada por los grandes maestros manieristas ${ }^{3}$.

Pero será a un amigo y colaborador suyo acaso, Juan Bautista Vázquez el Viejo y su círculo, que representa la implantación del italianismo en su fase de culto a una humanidad bella, equilibrada y fácil, a quienes atribuimos la realización de dichas piezas.

Su técnica parece basarse en la de Berruguete al fin de sus días; se ha explicado la correlación entre ambos, diciendo que Vázquez «es el desdoblamiento femenino del otro; su fase complementaria en sentido de armonía y elegancia, nunca desmentidas».

La corriente de italianismo que éste representa determinó una modificación de estilo, rejuveneciendo fórmulas, y «este impulso recaía sobre aquello en que Berruguete flaqueaba: la técnica, pero también recogió lo que este último había exaltado: la sensibilidad, norma feliz aseguradora del éxito» ${ }^{4}$.

La belleza constituye ahora el ideal, agradan las figuras gráciles de la nueva escuela, que se arquean suavemente, como desmayadas, con sus ropas adheridas al cuerpo, doblada una

\footnotetext{
${ }^{1}$ Boletín de la Sociedad Española de Excursiones, tomo X, 1902, p. 242

${ }^{2}$ R. Hocke: El manierismo en el arte europeo de 1520 a 1650 y en el actual. Madrid, 1961, p. 5.

${ }^{3}$ J. M. Azcárate: Alonso Berruguete, Dirección Gral de Bellas Artes, Valencia, 1963.

${ }^{4}$ M. Gómez Moreno: La escultura del Renacimiento en España, Barcelona, Gustavo Gili, 1931, pp. 79-80.
} 

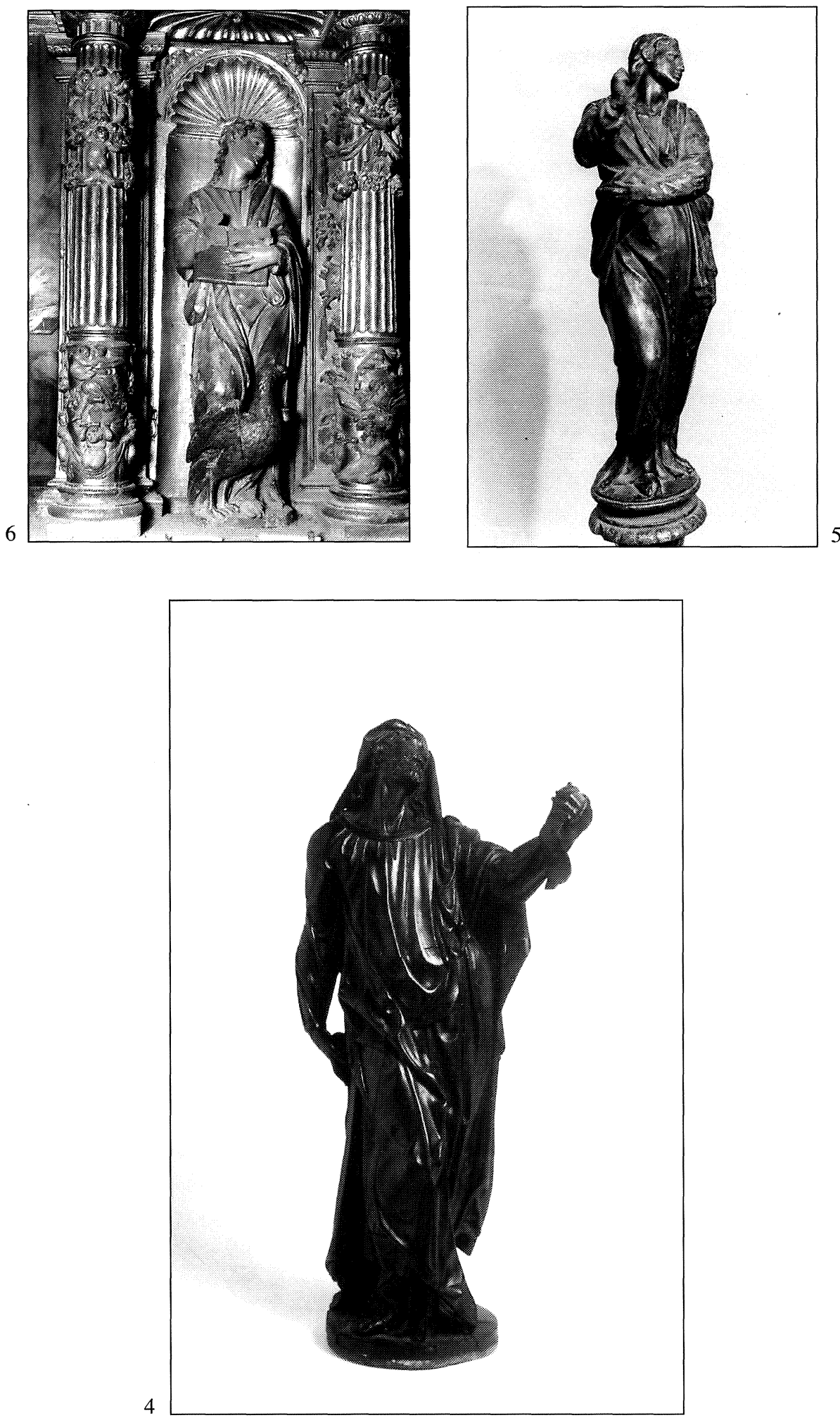

Fig. 4. Juan Bautista Vázquez, el Viejo (círculo de). Madrid. Instituto deValencia de Don Juan. Profeta. Fig. 5. Juan Bautista Váquez, el Viejo. Sevilla. Catedral. Tenebrario. Apóstol.

Fig. 6. Juan Bautista Vázquez, el Viejo. Mondejar (Guadalajara). Retablo (desaparecido). San Juan. 
pierna y rígida la otra, una mano posada y el otro brazo en acción; todo estudiado y repetido. Corrección, majestad y atractivo.

Juan Bautista Vázquez el Viejo nace posiblemente en la villa salmantina de Pelayos hacia 1525 , aparece como el más italianizado de nuestros escultores del siglo xvI, en la línea sansovinesca sin apenas reflejo del miguelangelismo imperante en sus contemporáneos.

Las primeras noticias documentales lo presentan por primera vez en Toledo el año de 1552, realizando con Vergara el Viejo la Anunciación de la Puerta del Reloj, en la catedral y contratando antes de 1555 el retablo de Mondéjar con el mismo artista, Covarrubias, maestro mayor de la catedral, y el pintor Correa.

Incluso pensando en su muy lógica formación con Berruguete, por el reflejo de su arte en muchas de sus obras (en numerosas figuras masculinas como los Apóstoles de Mondéjar, en algunas de sus composiciones: abrazo ante la Puerta Dorada del mismo retablo) y por su nombramiento como tasador del sepulcro de Tavera, los documentos conocidos no le citan entre sus colaboradores.

Activo en Toledo muy pocos años, fueron los suficientes para marcar con su huella la escuela toledana de escultura que hereda su buena técnica y su reposado manierismo, interpretación personal de los violentos contrapostos berruguetescos.

La primera noticia de Vázquez en Sevilla es la referente a su contrato para terminar el retablo de la Cartuja de la Cuevas el año de 1561, no concluido por Isidro Villoldo. La muerte de Balduque, el mejor escultor de Sevilla en la época y el esplendor de la ciudad debieron decidir su traslado definitivo a ella, convirtiéndose en el iniciador indiscutible de la escuela sevillana de imaginería.

Además de extraordinario escultor y grabador, fue posiblemente pintor, y en conjunto su arte sobresale por su corrección; caracterizándose sus obras en lo iconográfico por una profunda penetración en los temas propuestos, analizando sus valores formales e intentando identificarse con ellos, con acusado matiz idealista. Así las proporciones de las figuras son algo alargadas, agudizadas por su cabezas pequeñas, bien plantadas y suavemente movidas en actitudes manieristas de «contraposto». Se ha de destacar el conocimiento del tratamiento de los paños que en pliegues en bandas estrechas se ciñen al cuerpo, tendiendo a la diagonal y acentuando el movimiento en espiral de la figura. Su dibujo es justo y definidor, subrayando conjuntos y pormenores, y el modelado es suave y jugoso en la interpretación carnosa ${ }^{5}$.

Su obra en relieve no presenta tan bella calidad como sus obras exentas, ni en sus composiciones que no suelen exigir conocimientos especiales de la forma de agrupar los personajes, tallando las escenas principales en muy alto relieve. Su arte progresa al paso del tiempo, pues los mejores ejemplares de esta faceta de su actividad se realizan en su etapa sevillana.

Creemos debió ser en este último período de su producción artística cuando se realizaron las piezas en estudio, que están en la línea seguida por el maestro. Autor, junto a otros artistas, en la década de los 60 de obras como el Tenebrario para la Catedral sevillana, cuyo Apostolado es un curso completo de composición escultórica de origen berruguetesco por el desenfado en la ejecución y valentía de movimientos, pero bajo el hechizo de delicadezas expresivas de raíces idealistas; el Facistol del coro de la Metropolitana, cuyos Evangelistas son de mucho interés por el movimiento y valentía de sus ropajes e intenso matiz clásico de algunos, y la monumental escultura en bronce del Giraldillo, cuyo modelo en madera se le atribuye ${ }^{6}$.

La pieza que aparece en la colección con el $\mathrm{n}^{\mathrm{o}}: 4.297(38 \times 19 \times 12 \mathrm{~cm}$., en un estado de conservación aceptable, aunque presenta alguna grieta) hecha en madera de nogal, representando un Profeta es figura importante y digna por sus calidades artísticas. Majestuosa, con un

${ }^{5}$ M. Estella Marcos: Juan Bautista Vázquez el Viejo en Castilla y América. C.S.I.C., Madrid, 1990, pp. 5-29.

${ }^{6}$ J. Hernández Díaz: Imaginería hispalense del Bajo Renacimiento. Sevilla, 1951, p 29.

AEA, LXXVIII, 2005, 310, pp. 175 a 201 

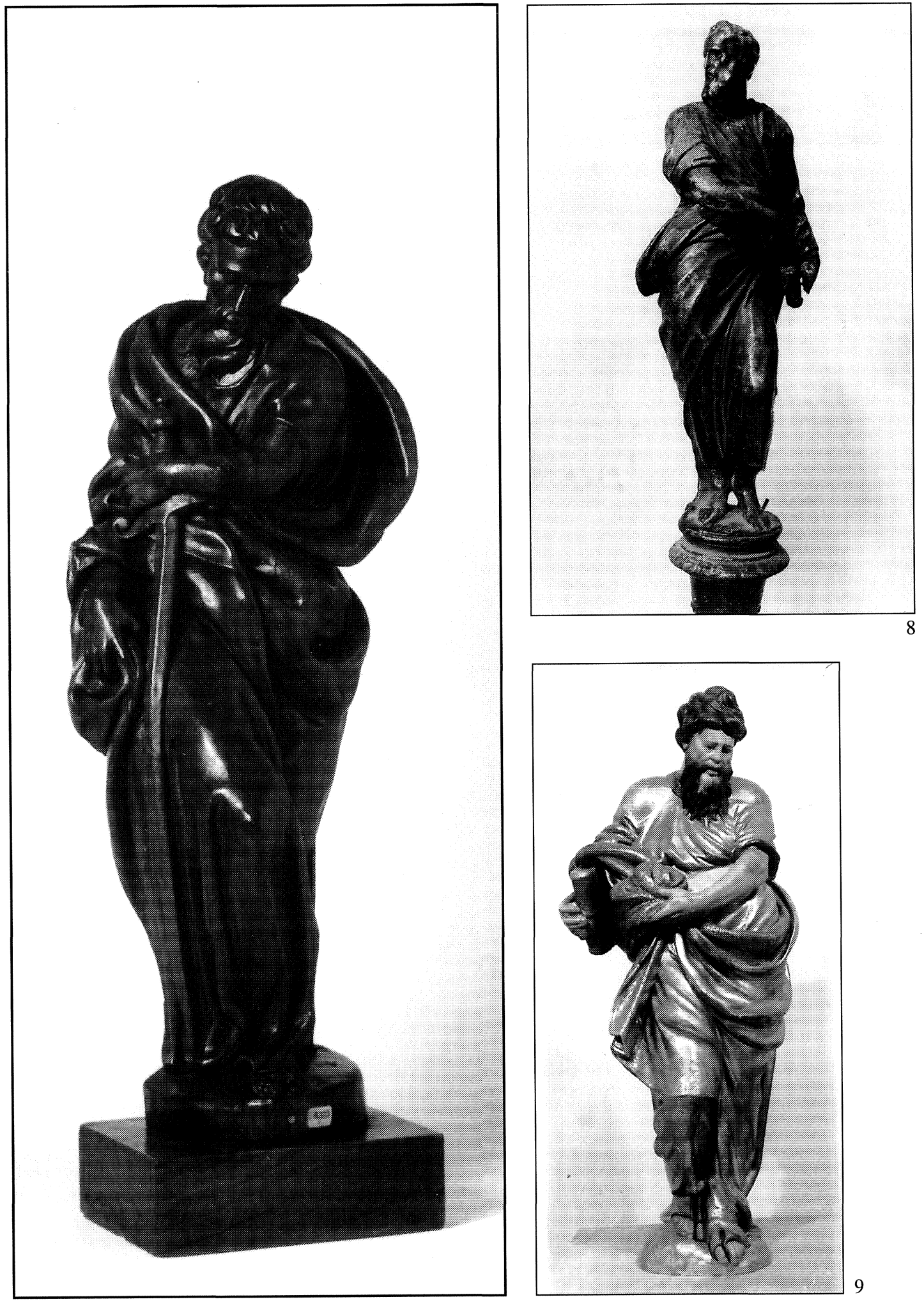

Fig. 7. Anónima. Madrid. Instituto De Valencia de Don Juan. S. Pablo.

Fig. 8. JuanBautistaVázquez, el Viejo. Sevilla. Catedral.Tenebrario. Apóstol.

Fig. 9. Anónimo. Toledo. Retablo de S. Román. San Lucas.

AEA, LXXVIII, 2005, 310, pp. 175 a 201 
quiebro en su verticalidad, está absorta en profunda contemplación, inclinando la cabeza en disposición de mostrar la filacteria que sostiene en su mano derecha. Presenta el brazo izquierdo pegado al torso en suave curvatura, sujetando el manto que diagonalmente corta la figura por el centro y aploma al contrarrestar la fuerza ascensional de la mitad inferior.

Muéstranos en su cabeza un profunda versión de serenidad y reposo, concentrado en el rostro, al que circunda una barba y cabellera hermosamente trabajadas, a pesar de la ocultación parcial de las mismas por el manto. Su bella faz de óvalo alargado y facciones correctas mira hacia abajo con los párpados entornados, destacando su recta nariz y la boca pequeña.

La escultura alcanza buen equilibrio de fondo y forma. Claramente inspirada en el arte italiano presenta la apostura de los personajes de dibujos del Zúccaro, quizás a través de las series de grabados flamencos que divulgaron sus composiciones. Y aquí procede recordar la cita de Pacheco, dice textualmente, que «vio a Pesquera y Baptista Vázquez labrar historias por estampas de los Zúccaros» ${ }^{7}$. Consultada la obra de Gere sobre los dibujos de Zúccaro, en concreto, nos atrevemos a señalar dos figuras de Profetas que podían haber sido su fuente de inspiración. Una el grabado del Musée Turpin de Crissé: Catalogue Guide, 1933, pág. 163, nº 314, lámina 106a; en cuanto a la facciones del rostro y colocación de ropajes. Otra un fresco en Santa María della Consolacione, Roma, lámina 76, modelo respecto a la disposición anatómica de la figura, ambas presentan la misma actitud al cargar el peso del cuerpo en la pierna derecha, mientras la izquierda aparece adelantada y doblada por la rodilla ${ }^{8}$.

En el plano de las realizaciones materiales apuntamos dos figurillas como modelos directos. Uno de los Evangelistas que coronan el citado templete del Facistol del coro sevillano, aunque muy abocetado, presenta el mismo balanceo al cargar el peso en la pierna derecha, mientras la izquierda, adelantada, se dobla por la rodilla, además el brazo derecho se levanta en disposición de mostrar algo mientras el izquierdo se ciñe al cuerpo. También coinciden en el movimiento y valentía de sus ropajes y en el matiz clásico de los mantos, que parecen tomados de obras romanas, llegando a cubrir la cabeza de las figuras.

Semejante disposición muestra uno de los Apóstoles del Tenebrario sevillano aunque varían en él la pierna que carga con el peso de la figura, así como el giro de la cabeza hacia el lado izquierdo.

La segunda pieza que analizamos aparece en el inventario del Museo con el número 4.294, y sus medidas son: $40 \times 22,5 \times 19 \mathrm{~cm}$. Realizada en madera de nogal presenta numerosas grietas. De fuerte influencia berruguetesca, templada por las corrientes manieristas italianas, es obra de gran calidad.

La figura parece sumergida en su visión íntima, y aunque contemple el aspecto del mundo exterior, su actitud, su ceño, los provocan las visiones de su conciencia. Tiene algo de esa impotencia de los protagonistas de Miguel Ángel aprisionados por el dolor. A semejanza del llamado «Esclavo que despierta», obra inacabada para la tumba de Julio II, de 1513-1520, presenta el cuerpo extendido en una perspectiva decididamente frontal, con la pierna derecha cruzada sobre la izquierda. Tiene la cabeza echada hacia atrás y vuelta a un lado, de forma que el que mira la escultura por su vista principal no la ve, revelándose en la vista lateral, que ofrece un hermoso aspecto secundario, muy similar al que presenta nuestra pieza.

El artista realiza el Profeta con proporciones algo alargadas, agudizadas por su cabeza pequeña bien plantada e intensamente movida en actitud manierista de «contraposto». La línea directriz de la escultura arranca de los pies y se lanza hacia la altura por la cabeza que queda llameante.

\footnotetext{
${ }^{7}$ F. J. Sánchez Cantón: Fuentes literarias para la historia del Arte español, recoge el testimonio de Pacheco.

${ }^{8}$ J. A. Gere: Taddeo Zúccaro. London, Faber and Faber, 1969.
}

AEA, LXXVIII, 2005, 310, pp. 175 a 201 
Para dinamizar el contrapunto de la imagen flexiona una rodilla, y la otra pierna retraída imprime movimiento de rotación a la figura, con lo cual todo adquiere una gran movilidad. Dentro de la misma figura se busca el contraste entre el pecho robusto, y la cabeza anhelante y entrecejuda. Su rostro magro, cuyos ojos se hunden cavernosos en trazado oblicuo, el tratamiento de los paños que en pliegues en bandas estrechas se ciñen al cuerpo, tendiendo a la diagonal y acentuando el movimiento en espiral de la imagen.

Como modelo proponemos una de las figuras que integran el Tenebrario de la catedral hispalense, así como la figura de San Juan Evangelista del retablo de Mondéjar, ambas obras de Vázquez. Mayor afinidad psicológica con el San Juan Evangelista reflejando ese dejarse llevar anímico de ambas figuras en la considerable torsión del cuello que inclina la cabeza hacia el lado derecho; mientras que el movimiento centrípeto de las extremidades superiores coincide con el efectuado por el Apóstol del Tenebrario.

Además hay similitudes en la disposición de los pliegues de sus vestiduras, coincidiendo especialmente en las vueltas del manto de la mano izquierda de San Juan Evangelista y el pliegue inferior que el movimiento de contraposto delinea en la túnica del Profeta, ambos configurados en doble vuelta.

La tercera obra que analizamos figura en el inventario del museo con el número 4.323 , y sus medidas son: $38 \times 15 \times 10 \mathrm{~cm}$. Su estado de conservación, al igual que el de las anteriores, es aceptable, a pesar de presentar alguna grieta.

Esta figurita de San Pablo fue atribuida por el profesor Gómez-Moreno al escultor Diego de Pesquera, activo en Granada y Sevilla entre 1563 y $1580^{\circ}$. Procedente de Sevilla, hecha en madera de nogal, resulta elegante con el plegar de ropas ceñidas al cuerpo, abrazando la espada, que cede a la presión arqueándose, y con equilibrio de masas, rebuscado y formulario; pero, además, en este caso lo chupado de la figura por abajo responde al canon berruguetesco, aplicado por Vázquez a los apóstoles del tenebrario de la catedral sevillana, donde pudo inspirarse Pesquera.

La imagen aparece impetuosa y se representa en posición frontal, aunque con inicio de giro hacia el lado izquierdo, y postura andante, con la rodilla derecha plegada y la pierna izquierda hacia atrás. En cuanto al magro rostro presenta un gesto noble, en actitud pensativa y con la cabeza inclinada ligeramente hacia abajo. La expresión de los ojos demuestra una cierta tristeza, como si fuera el reflejo de sus sentimientos. Destaca la talla del pelo ahuecado, bellamente ondulado, que deja ver el conocimiento que tenía el artista que ejecutó esta obra de los grandes maestros italianos.

Nosotros consideramos que recuerda mucho al desconocido autor del retablo de San Román de Toledo, concretamente al artista identificado por algunos como uno de los dos Velasco, aunque la firma aparecida en la restauración de este retablo ha complicado la autoría. Concretamente a la figura del evangelista San Lucas situado en el ático de la entrecalle del Evangelio. Las vestiduras de ambas tallas presentan sinuosos pliegues de vueltas redondeadas con concavidades marcadas, que se pegan al cuerpo mientras los sujetan en la cadera con la mano izquierda. Tanto la túnica como el manto acentúan el movimiento «apasionado» de la figura. Destaca la posición inestable o, mejor dicho, la actitud de contraposto que podría equipararse a la maniera de Berruguete o asemejarse a las formas miguelangelescas, aunque las figuras sean menos corpóreas ${ }^{10}$.

Las reducidas dimensiones de nuestras piezas, su evidente descontextualización y asuencia de documentación impiden conocer su procedencia y dificultan su clasificación. No obs-

\footnotetext{
${ }^{9}$ Gómez-Moreno, M.: Diego Pesquera, escultor. A.E.A., Madrid, 1955, nº 112, pp. 289-304.

${ }^{10}$ Quadrivium. Patrimonio mueble restaurado en Castilla-La Mancha. Colección Arte e Imagen ${ }^{\circ}$ 6, Archivo Histórico Provincial de Toledo, mayo-junio, 1999, pp. 59-63, 237-238.
} 
tante y como hemos visto, dadas las comparaciones y semejanzas atribuimos estas obras a artistas del círculo o influencia de Alonso Berruguete, pues en todas ellas puede rastrearse la impronta genial de ese peculiar modo de hacer la figura humana utilizando un canon alargado, a menudo torsionando al extremo los cuerpos y realizando rostros desencajados y hasta violentos. Un estilo característico que representa como ningún otro el manierismo hispano, y que, por sí mismo y en sus múltiples seguidores y epígonos, marcará el camino a seguir por el realismo de la imaginería barroca española.

Pero si nuestras dos figuras de Profetas, por sus coincidencias con algunas del Facistol y Tenebrario sevillanos, así como con otras del retablo de Mondejar, e incluso con dibujos del Zúccaro, están en la línea más depurada de Juan Bautista Vázquez, la tercera, correspondiente al Apóstol, presenta una corporeidad y una energía que la acercan más al trabajo de otros artistas del foco toledano como los Velasco.

CARMEn Fernández AHIJAdo I.E.S. Leandro Fernández de Moratín (Guadalajara)

\section{UNA REMUNERACIÓN NO CONVENCIONAL EN EL PAGO DE UN RETABLO TARDOGÓTICO NAVARRO}

Desconocemos el lugar de nacimiento del pintor Diego Polo aunque no creemos que fuera la villa de Puente la Reina ${ }^{1}$. Sabemos que mantuvo en la citada villa su taller hasta su muerte ${ }^{2}$. Nuestra hipótesis es que el maestro Polo era originario de Aragón, donde debió formarse en el entorno del pintor Martín Bernat. Su llegada a Navarra pudo producirse como consecuencia de la asociación con el entallador maestro Terín. Tampoco sabemos su fecha de nacimiento pero intuimos que debía de estar cercana a la de su colaborador —entre 1460 y 1465 - ${ }^{3}$.

Debió instalar su taller en Puente la Reina a finales del siglo xv, momento en el que la villa decidió sustituir su vieja iglesia románica de Santiago por la actual — terminada a fines del siglo XVI— ${ }^{4}$, por esta razón Diego Polo no trabajó, que sepamos, para las parroquias - Santiago y San Pedro- de Puente la Reina ${ }^{5}$. Debió de ser feligrés de la parroquia de San Pedro de Puente la Reina, aspecto que basamos en la presencia de su vicario don Pedro de Sarría como testigo de su parte en el contrato de Legarda, en el que incluso - el citado clérigo- llega a firmar en nombre del maestro puesto que éste no sabía escribir ${ }^{6}$. En Puente la Reina casó

\footnotetext{
${ }^{1}$ Después de investigar en los archivos parroquiales de Santiago y San Pedro de Puente la Reina - libros de bautismos y defunciones-, no hemos encontrado noticias sobre el linaje de los Polo en la villa. Existe un reconocimiento de hidalguía a favor del apellido Polo, datado en Peralta en 1566 - J. M. De Huarte y de Jáuregui y J. de Rújula y de Ochotorena, Nobiliario del Reino de Navarra, Madrid, 1923, p. 433-, aunque no creemos que tenga demasiada relación con el maestro Diego Polo.

${ }^{2}$ En la querella por el retablo de San Juan Bautista de Obanos, al final de sus días, se menciona que Diego Polo era vecino de Puente la Reina - J. R. Castro Álava, Cuadernos de Arte Navarro, Pamplona, 1944, pp. 35-38-

${ }^{3}$ C. Fernández Ladreda, «Maestre Terín, un escultor activo en Navarra en torno al 1500», Actas del Congreso Internacional sobre Gil Siloe y la escultura de su época, Burgos, 2001, pp. 539-540.

4 J. M. Jimeno Jurio, «Puente la Reina. Iglesia de Santiago. Del Románico al Renacimiento», Príncipe de Viana, ${ }^{\circ} 218$, Pamplona, 1999. Al concluirse las obras de la parroquia a finales del siglo xvi, los muebles litúrgicos comenzaron a realizarse a partir del siglo xviI, obviamente, en estilo Barroco.

5 Además de la reseña sobre la parroquia de Santiago debemos considerar que la parroquia de San Pedro, de la misma villa - de la que seguramente Diego Polo era feligrés - era una iglesia pequeña - de una sola nave- que sería totalmente reformada en el siglo xviII merced al legado del indiano Miguel Francisco de Gambarte — G. García Gaínza y otros, $C a$ tálogo..., vol. $\mathrm{V}^{* *}$, pp. 526-532-.

6 J. R. Castro Álava, Cuadernos..., p. 43.

$A E A$, LXXVIII, 2005, 310, pp. 175 a 201
} 